\title{
Risk Perceptions and Management Strategies of Rice Smallholders in the Mekong Delta, Vietnam
}

\author{
Huy Duc Dang ${ }^{1 *}$, Thuyen Thi Pham² \\ ${ }^{1}$ Department of Business Administration, Economics Faculty, Nong Lam University, HCMC, Vietnam \\ ${ }^{2}$ Department of Economics, Economics Faculty, Nong Lam University, HCMC, Vietnam
}

Received: 9 February 2021

Accepted: 10 April 2021

\begin{abstract}
This empirical study investigates Vietnam rice farmers' risk perceptions, risk management strategies, and the relationship with socio-demographic antecedents. Data were randomly collected from 194 farmers in An Giang province - the rice bowl of the Mekong Delta region. A flexible combination of exploratory factor analysis and principal component analysis was used to elucidate farmers' opinions towards risks and their corresponding management strategies. For risk perceptions, low and unstable selling price, unstable input supply, high and fluctuating input price, lack of health protection in pesticide use, and poor quality pesticides were perceived as the top five most important sources of risk in the studied area. For management strategies, make use of the combined harvester, adoption of certified varieties, selecting prestigious partners, increase the percentage of mechanization, matching production schedule with neighbors, and using climate-adaptive varieties were the most pivotal strategies to mitigate risks. The regression results showed that some idiosyncratic strategies can be driven by multiple perceptions, either negative or positive. The study provides empirical evidence to suggest tailored agricultural policies to reinforce farmers' resilience against risks at different levels.
\end{abstract}

Keywords: agriculture, rice farming, risk perception; risk management, sources of risk

\section{Introduction}

Farmers' perceptions and their responses to risks have been proven to be unarguably vital for the understanding of risk behaviors [1-5]. As such, risk perceptions and management strategies have been studied extensively and serve as valuable inputs for different stakeholders and policymakers. However,

*e-mail: simon.hdang@gmail.com perceived risk patterns are highly contextual and not the same across systems and geographical regions [46], let alone the incongruity of the perceived levels $[7,8]$. Through literature reviews, it has come to our attention that very limited studies have investigated risk perceptions and management strategies of rice - an important cash crop in developing countries, especially in South East Asia regions home to the World second and third largest rice exporters in 2019 - Thailand and Vietnam. As the World's thirdlargest rice exporter, understanding perceptions about 
risks and management strategies in rice farming will not only boost agricultural sustainability but also provide benefits to a more sustainable livelihood for rice producers, particularly small-scale farmers. For that reason, this paper sets out to provide empirical insights into (1) Vietnamese rice farmers' perceptions of risk and risk management strategies; (2) the relationship between farm and farmers' sociodemographic characteristics and farmers' perceptions of risk and risk management strategies in rice farming. Results from this study are expected to disseminate useful information for farmers and policymakers in designing sustainable development strategies in this non-stop changing farming environments. The paper is unique in a way that it offers insights into risk perception and management strategies of rice farmers in Vietnam which is scarce to date in the current body of literature.

The study is organized in the following orders. First, we elaborate on the conceptual framework in use in section 2. Section 3 describes studied methods and data, while section 4 presents the results and discussion derived from the descriptive and regression analyses. The final section concludes the results of the study and mentions the limitations.

\section{Conceptual Framework}

The concept of subjective risk perception has been proposed by Sjöberg, et al. [9] rooted in the psychometric paradigm as complementary to describe individual behaviors where the expected utility theory fails to address [1]. Ever since, empirical studies have been successfully provided evidence to conclude that risk perceptions play a critical role on decision-making behaviors [2, 4-6, 8, 10]. Thus, understanding risk perception and its antecedents are considered pivotal in untangling individuals' decision-making processes.

First, the present study employed the model of decision-making environment of van Raaij [11] as the theoretical foundation as it has been successfully used in analyzing risks in various industries such as dairy farming [1], and fish-farming [4, 5], shrimp farming [8], and livestock farming [2, 6]. Second, we incorporated the multidimensional risk assessment framework of Crane, et al. [12] which categorizes risks into five specific categories namely production, marketing, financial, legal, and human risks, and was also applied in recent empirical risk-related studies $[4,10]$.

Fig. 1 illustrates the modified model used in this research. The model indicates the relationship between farm and farmers' characteristics and risk perceptions in agriculture, and then the influence of risk perceptions on economic behavior (or subsequent management strategies). The framework also reveals a spectrum of potential management strategies to confront related risks.

\section{Methods and Data}

\section{Sample and Data}

Data are collected in July 2019 in An Giang province, known as "the rice bowl" of the Mekong Delta (Fig. 2). Rice farming in the region is commonly practiced in the form of three main crop seasons: the winter-spring, the summer-fall, and the fall-winter season. The stratified sampling method is employed to recruit farmers from the list of potential rice farming households provided by the local agricultural extension office. In An Giang province, Thoai Son and Chau Thanh are identified as the main rice-producing districts with the characteristics that satisfy our data frame. Prior to conducting the survey, a draft questionnaire is sent to one extension agent, and three randomly selected farmers to test its clarity and relevance. After that, a team of two extension agents (commune level) and 10 enumerators helps to facilitate the data collection process. The study encounters difficulty in locating the right farmers on the acquired list due to the lack of properly written address and erroneous GPS locating services. Fortunately, local farmers are so friendly and helpful in referring their colleagues in the surrounding areas, which contributes to the inadvertent usage of

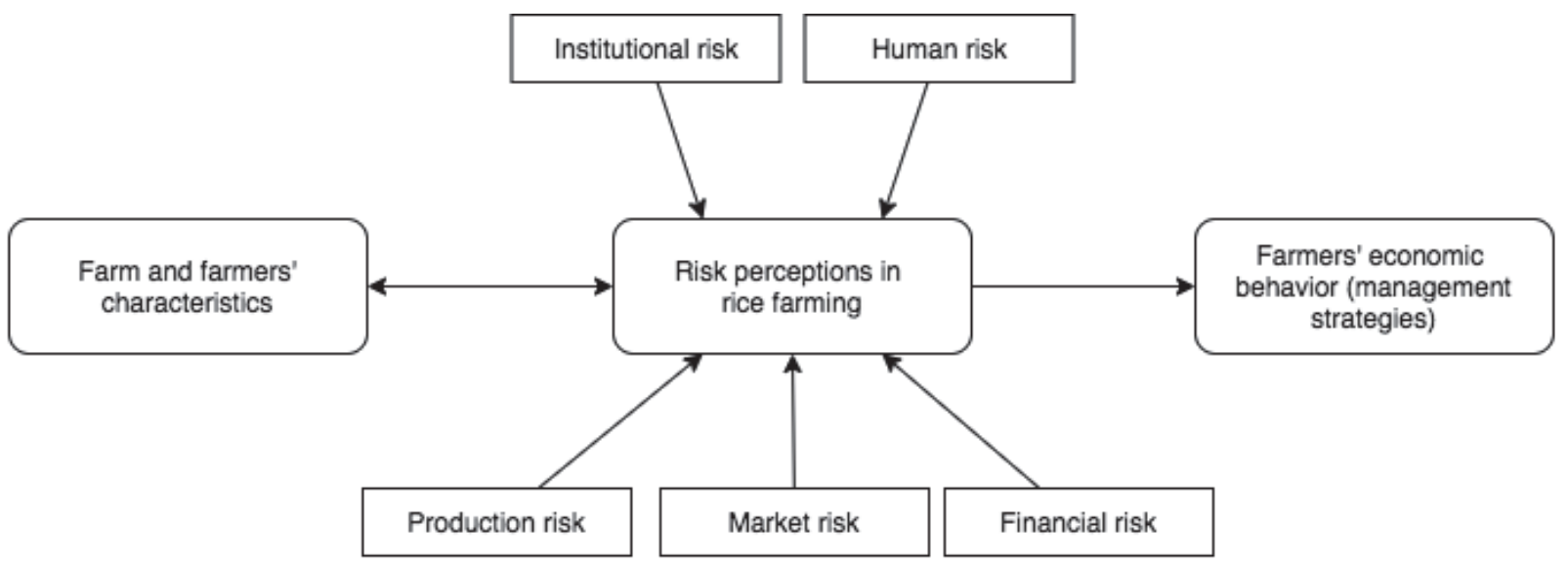

Fig. 1. The studied framework modified from van Raaij [11]. 


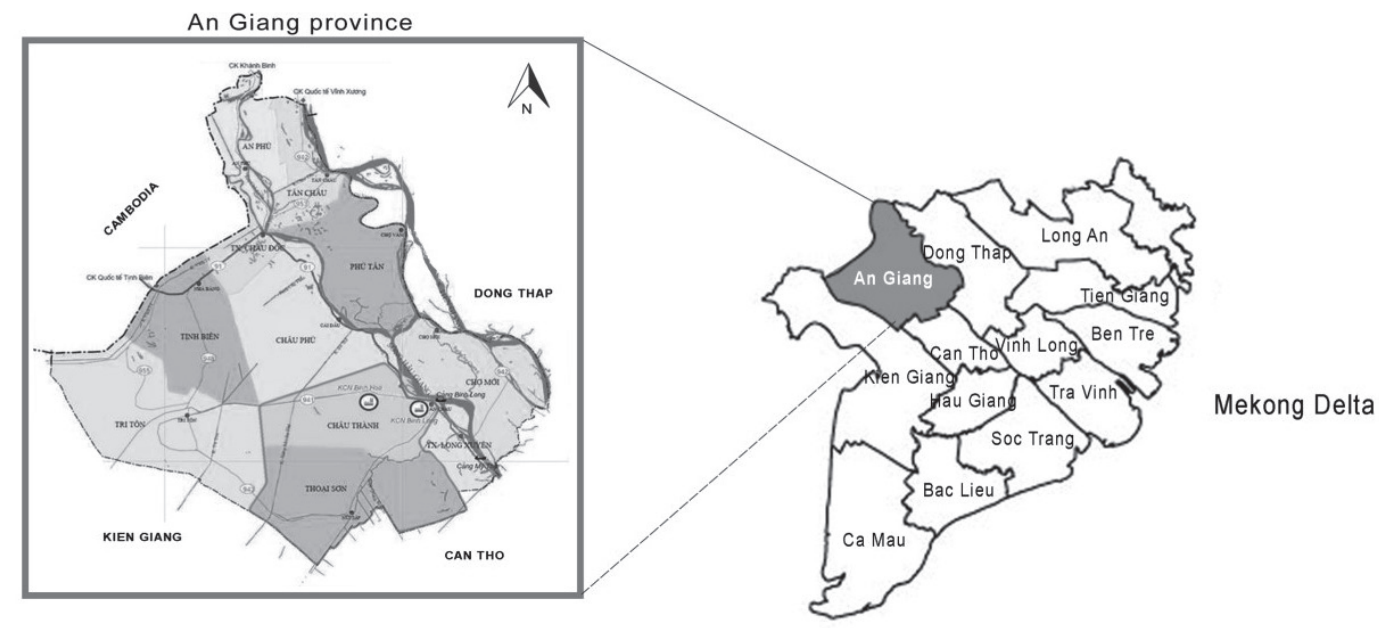

Fig. 2. The study area. Source: author's elaboration.

the snowball method, complementary to the main data collecting method. Because of that, we finally manage to collect a total of 194 observations. Raw data are preprocessed at the end of the day to avoid missing valuable information.

\section{Econometric Models}

The study employed descriptive methods, factor analysis method, and multiple linear regression models. First, the descriptive statistics were useful in classifying the importance of distinct risk perceptions and management strategies by the magnitude of their means. Next, factor analysis and regression models were applied to explore the relationship between risk perceptions and management and socio-demographic characteristics of smallholders. For perceptions of risk sources, the principal component analysis was carried out in designated risk dimensions predefined (i.e. production, market, finance, institution, and human) by the mutual agreement between both experts and key farmers. However, due to the complication of the overlapping effects of risk management strategies, an exploratory factor analysis procedure was used. The latent root criterion (Eigenvalue $>1$ ) decides on the number of factors retained for subsequent regression models. The varimax rotation extraction method was selected for the factor matrix. Prior to the factor analysis, Kaiser-Meyer-Olkin (KMO) measure of sample adequacy and Barlett's test of sphericity were used to check the concordance for the application condition of factor analysis. KMO of at least 0.5 and factor loadings of 0.4 and above were considered significant [13]. Standardized factor scores were saved for subsequent regression analysis. The ordinary least square (OLS) regression for perceived risks and management strategies can be presented as follow:

$$
R P_{i, t}=f\left(X_{t}, \varepsilon_{t}\right)
$$

and

$$
R M_{j, t}=f\left(X_{t}, R P_{i, t}, e_{t}\right)
$$

...where

$R P_{i, t}$ : standardized factor scores for sources of risks $(\mathrm{i}=1,2, \ldots, 7)$

$R M_{j, t}:$ standardized factor scores for risk management strategies $(\mathrm{j}=1,2, \ldots, 8)$

$X_{t}:$ is the set of explanatory variables described in Table 1.

$\varepsilon_{t}$ and $e_{t}$ are error terms of Eq. 1 and 2, respectively.

The factor analyses were computed by SPSS version 24 and regressions were estimated using Stata version 14. The basic assumptions of OLS were tested for possible violations. Durbin-Watson statistics revealed no problem of first-order autocorrelation. The variance inflation factors (VIF) were calculated to detect any multicollinearity. Heteroscedasticity was checked using the Breush-Pagan test. The regressions that violated the assumption of homoscedasticity of the error terms were re-estimated using the robust standard errors.

\section{Results and Discussion}

\section{Demographic and Farm Characteristics}

Table 1 delineates the descriptive statistics of the studied sample. The majority of farmers interviewed were male $(90.21 \%)$. The average age was 48 (in the range of 27-78). The average education attainment was 6 years, most farmers finished elementary and above $(58.25 \%)$. The average farming experience was 18 years. $91.24 \%$ received at least one extension training in the current year. The average farm size was 2.65 ha. About $47 \%$ of farmers were a member of a cooperative. $33 \%$ of farmers received at least one additional income source besides rice farming. 


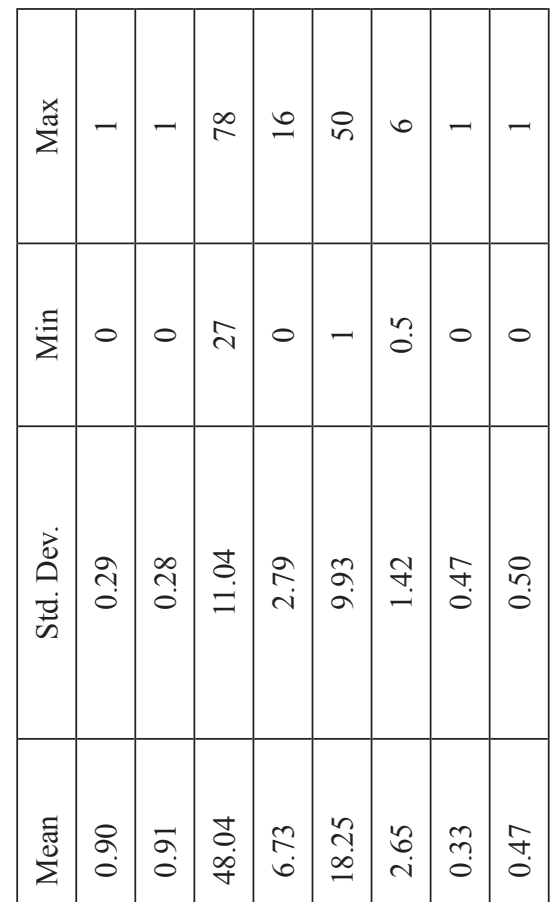
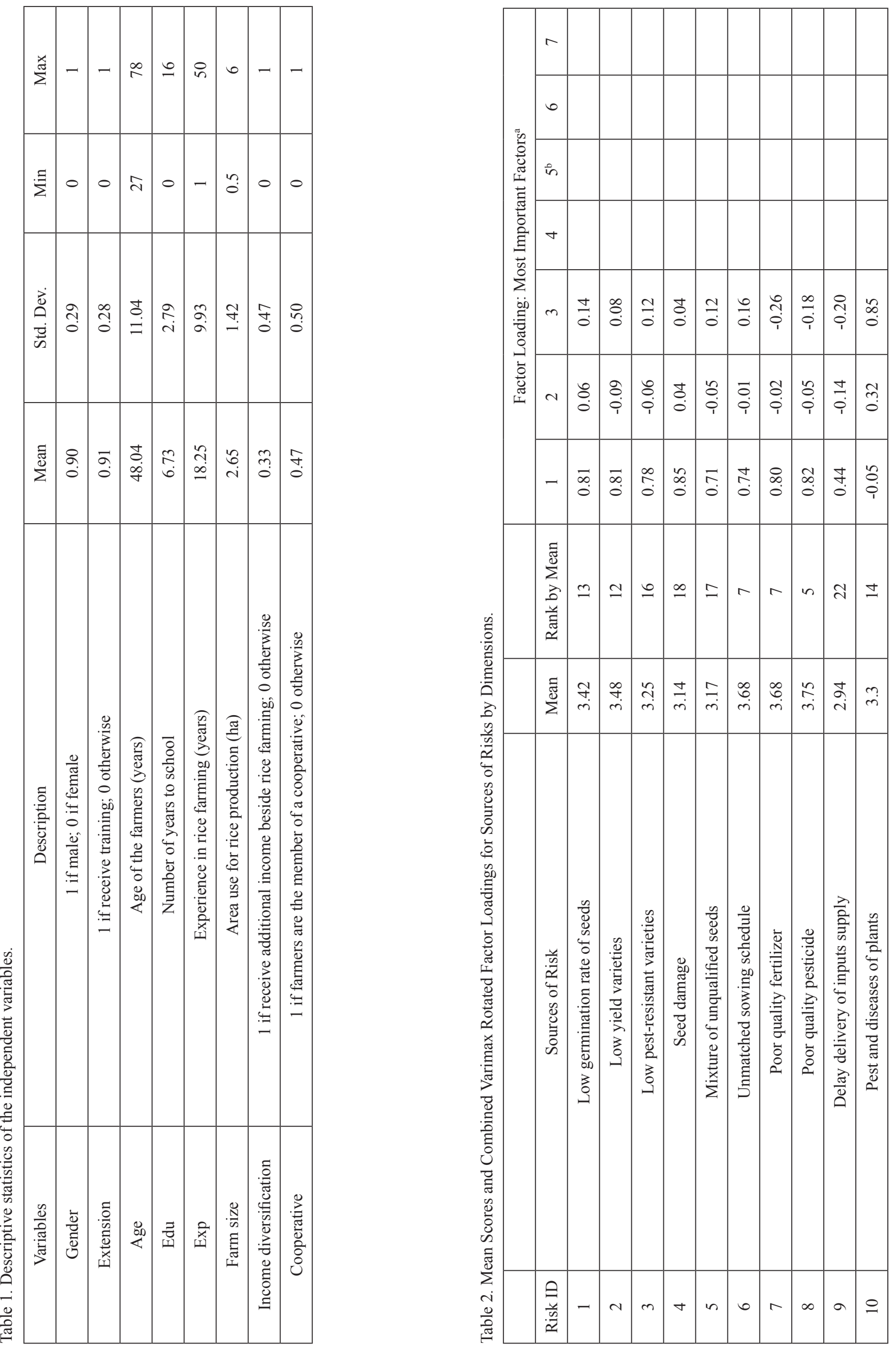

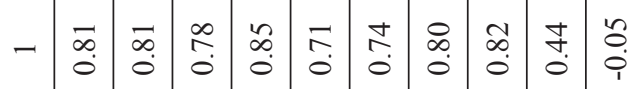

Еี

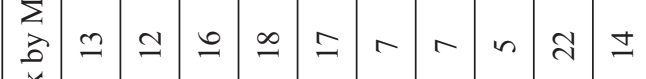

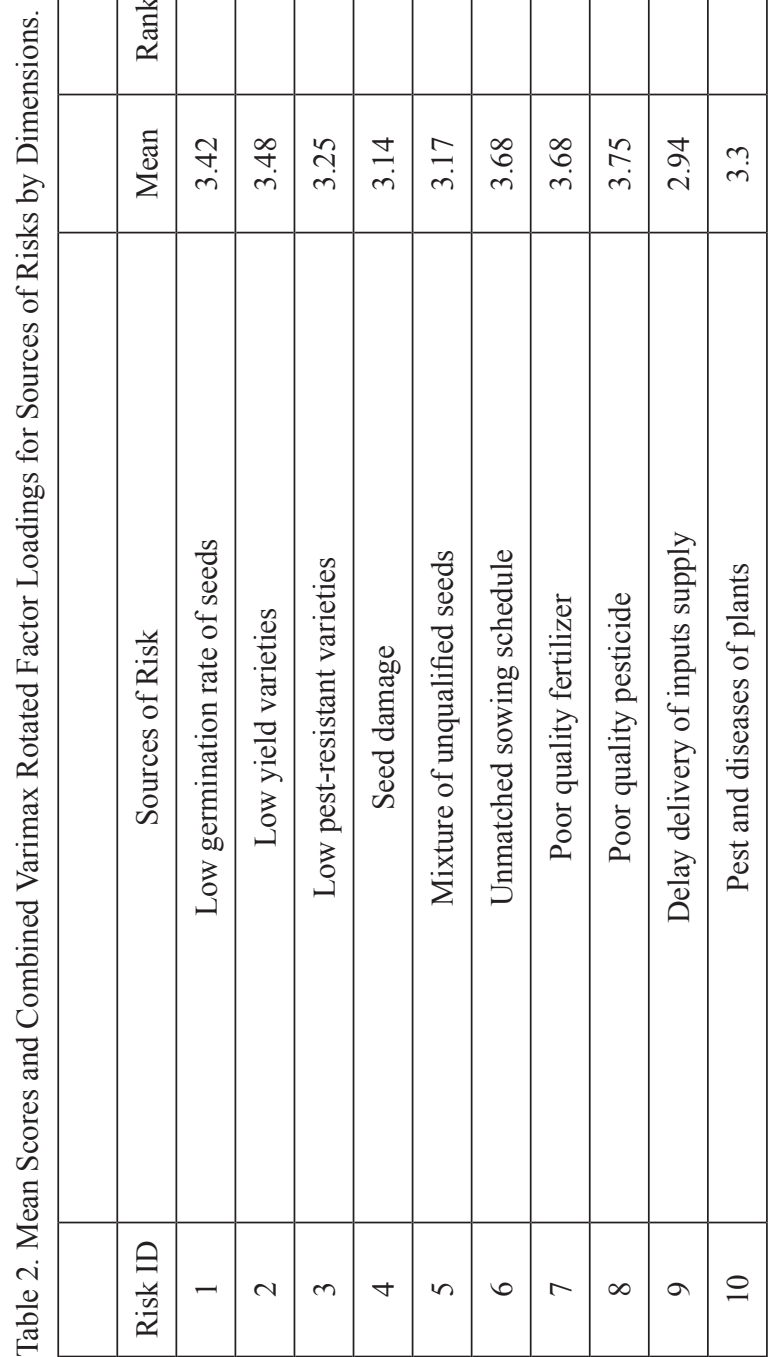




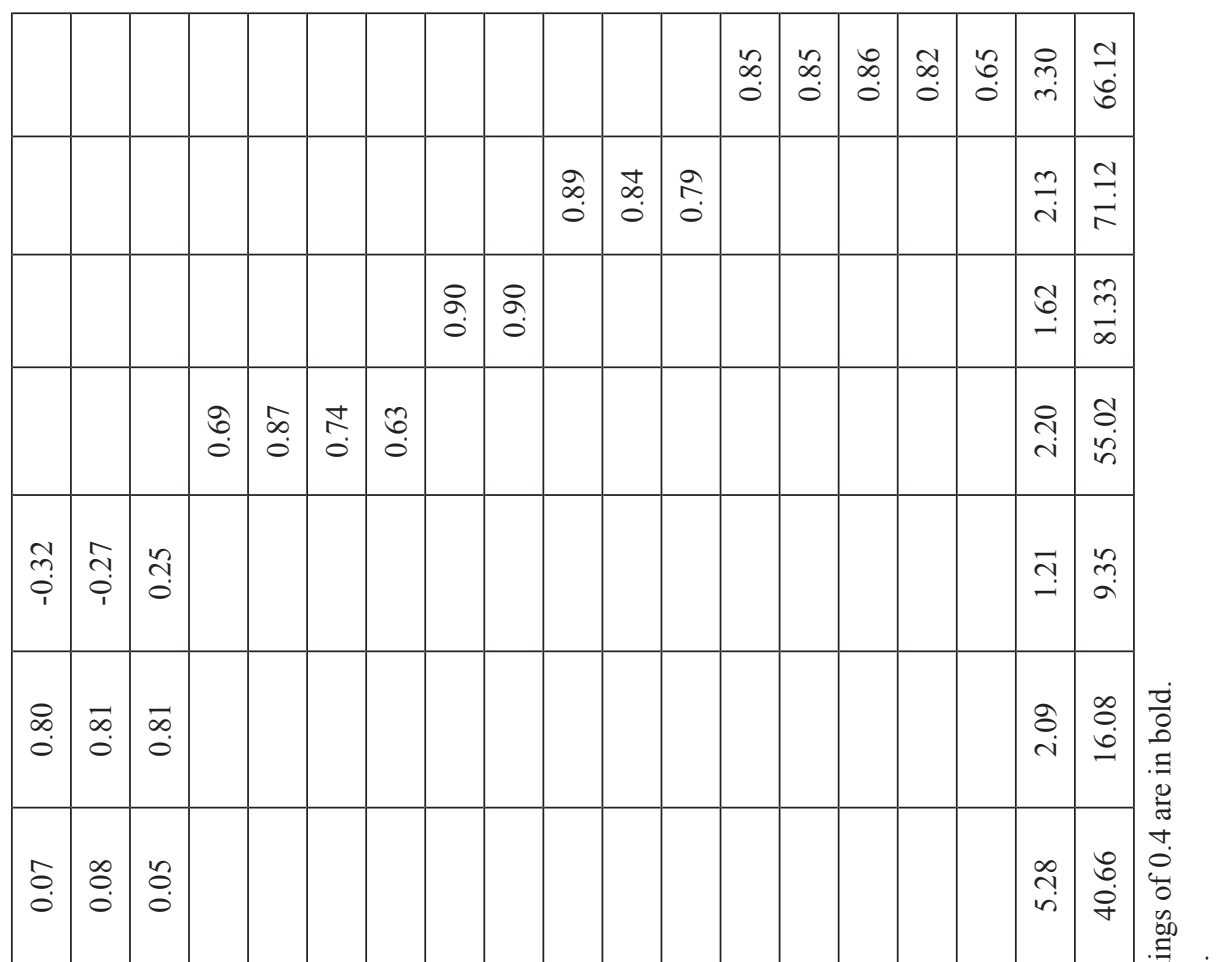

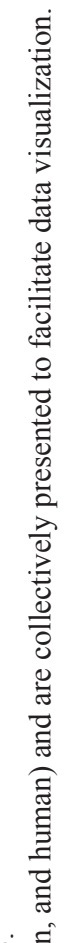

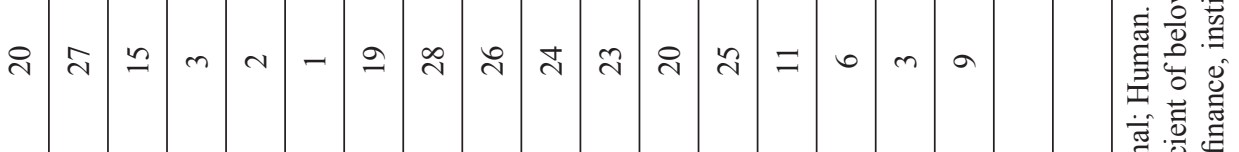

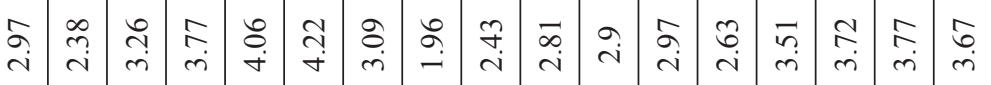

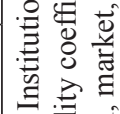

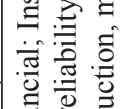

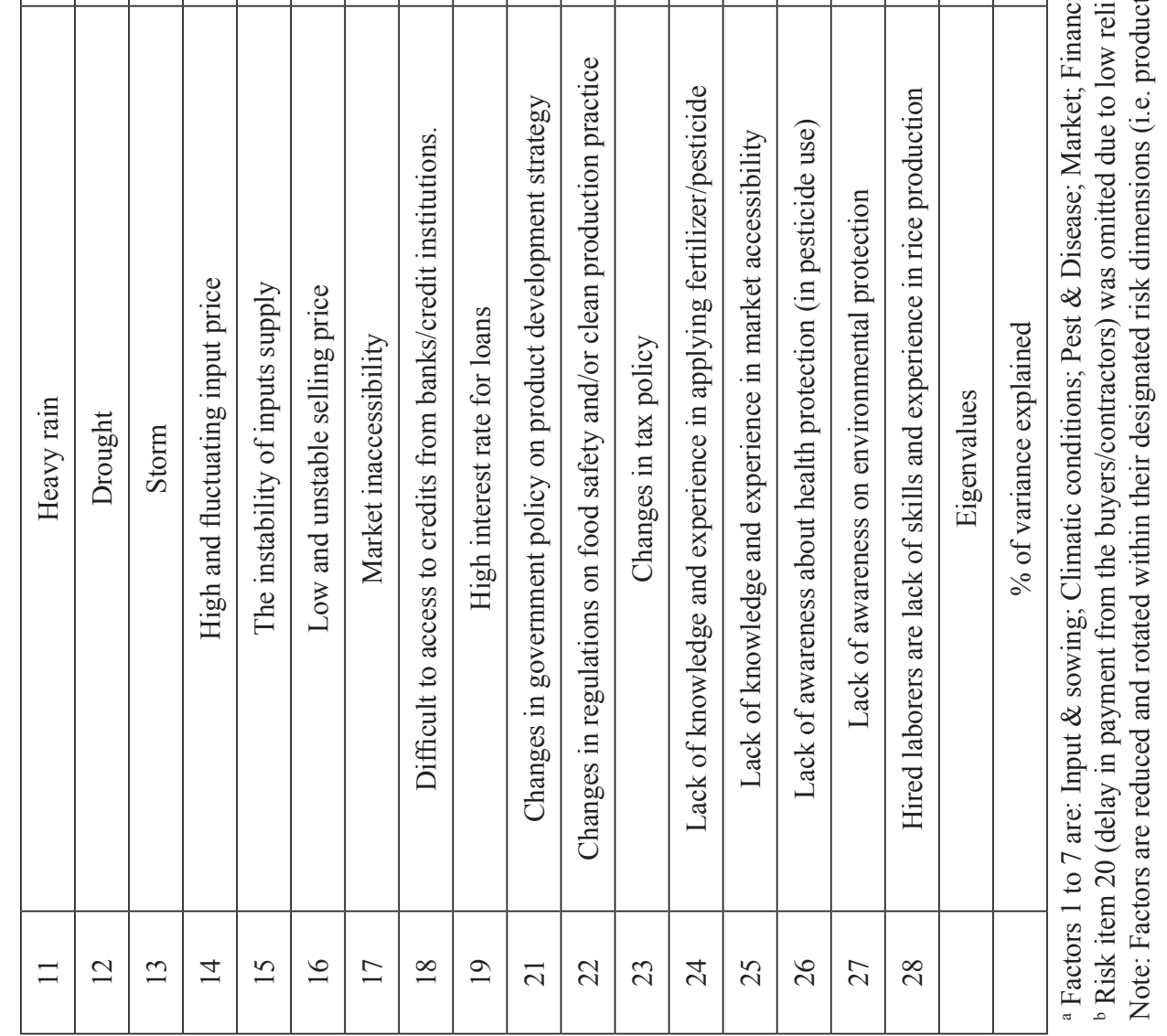




\section{Perceptions of Risk Sources}

In total, 28 sources of risk were analyzed. To measure farmers' perceptions about the impacts of risks on their income and productivity, we adopted a 7-point Likert scale ranging from 1 - very low impact to 7 very high or severe impact.

The second and fourth columns of Table 2 show the names and ranks of risk factors, respectively, by dimensions. Table 3 illustrates detailed means, standard deviations, and corresponding ranks by mean in the decreasing order in terms of the magnitude of impacts.
Surprisingly, small rice farmers in the region seem to experience favorable farming conditions, as a result, their risk perceptions only range from moderate concern (average score 4.0-5.0) to low concern (average score $3.0-4.0$ ), and very low concern (average score $<3.0$ ).

The first cluster consists of low and unstable selling price, and the instability of inputs supply, with average scores of 4.22 and 4.06 , respectively. Volatile selling prices were identified as the top-ranked source of risk as about $40 \%$ of farmers perceived this risk is of great concern (score 6-7). This is similar to fish farming [4,5]. Selling prices have always been and will continue to be of great concern for rice farmers, particularly for those without contractual partnerships [14]. For the

Table 3. Means, Standard Deviations and Ranks of Risk Sources.

\begin{tabular}{|c|c|c|c|c|c|}
\hline Risk ID & Sources of Risk & $\mathrm{N}$ & Mean & Std. Dev. & $\begin{array}{c}\text { Rank by } \\
\text { Mean }\end{array}$ \\
\hline 16 & Low and unstable selling price & 194 & 4.22 & 2.23 & 1 \\
\hline 15 & The instability of inputs supply & 194 & 4.06 & 2.16 & 2 \\
\hline 14 & High and fluctuating input price & 194 & 3.77 & 1.97 & 3 \\
\hline 26 & Lack of awareness about health protection (in pesticide use) & 194 & 3.77 & 2.01 & 3 \\
\hline 8 & Poor quality pesticide & 194 & 3.75 & 2.10 & 5 \\
\hline 25 & Lack of knowledge and experience in market accessibility & 194 & 3.72 & 1.86 & 6 \\
\hline 6 & Unmatched sowing schedule & 194 & 3.68 & 2.03 & 7 \\
\hline 7 & Poor quality fertilizer & 194 & 3.68 & 2.01 & 7 \\
\hline 27 & Lack of awareness on environmental protection & 194 & 3.67 & 1.97 & 9 \\
\hline 28 & Hired laborers are lack of skills and experience in rice production & 194 & 3.56 & 2.11 & 10 \\
\hline 24 & Lack of knowledge and experience in applying fertilizer/pesticide & 194 & 3.51 & 2.1 & 11 \\
\hline 2 & Low yield varieties & 194 & 3.48 & 2.19 & 12 \\
\hline 1 & Low germination rate of seeds & 194 & 3.42 & 2.28 & 13 \\
\hline 10 & Pest and diseases of plants & 194 & 3.3 & 2.2 & 14 \\
\hline 13 & Storm & 194 & 3.26 & 2.22 & 15 \\
\hline 3 & Low pest-resistant varieties & 194 & 3.25 & 1.90 & 16 \\
\hline 5 & Mixture of unqualified seeds & 194 & 3.17 & 2.17 & 17 \\
\hline 4 & Seed damage & 194 & 3.14 & 2.01 & 18 \\
\hline 17 & Market inaccessibility & 194 & 3.09 & 1.9 & 19 \\
\hline 11 & Rain & 194 & 2.97 & 2.1 & 20 \\
\hline 22 & Changes in regulation on food safety and/or clean production practice & 194 & 2.97 & 1.65 & 20 \\
\hline 9 & Delay delivery of inputs supply & 194 & 2.94 & 1.93 & 22 \\
\hline 21 & Changes in government policy on product development strategy & 194 & 2.9 & 1.6 & 23 \\
\hline 20 & Delay in payment from the buyers/contractors & 194 & 2.81 & 1.88 & 24 \\
\hline 23 & Changes in tax policy & 194 & 2.63 & 1.81 & 25 \\
\hline 19 & High interest rate for loans & 194 & 2.43 & 1.82 & 26 \\
\hline 12 & Drought & 194 & 2.38 & 1.86 & 27 \\
\hline 18 & Difficult to access to credits from banks/credit institutions & 194 & 1.96 & 1.72 & 28 \\
\hline
\end{tabular}


second-most impactful risk - input supply, about 37\% of farmers perceived this risk as of great concern. Due to the characteristics of smallholders, farmers often can not reap the benefit of discount from large orders from big suppliers, which force them to depend on multiple small and local suppliers with limited capacity.

The second cluster includes 17 sources of risk with the average scores ranging from 3.09 to 3.77 and rank from 3 to 19 on the list. The next 9 sources of risk with scores from 1.96 to 2.97 with corresponding ranks of 20 to 28 constitute the third cluster of risks (see Table 3 for the full list of risk ranking).

In the second cluster, high and fluctuating input price secures the third-most important spot. The underlying reason might also be shared with the second-most important source. Small farmers hardly order inputs in bulk in order to secure the purchasing prices, thus buying on-demand always accompanies float prices. The two next critical sources of risk involve awareness about health protection in pesticide use and poor quality pesticide. Similar to Thailand [15], applying excessive quantities of synthetic pesticides to control the risk of pests and diseases has been ubiquitous in Vietnam. In spite of the obvious risk-increasing effects of pesticide and insecticides [16-18], farmers' awareness of health risks are relatively low in accordance with neglecting safe handling practices. In fact, about $74 \%$ of farmers considered this source of risk moderate to low, which could lead to underestimation of mitigation strategies. On the contrary, $72 \%$ of studied farmers were relatively confident in the quality of pesticides used by rating the risk of using poor quality pesticides between moderate to very low. This might hint that farmers either are knowledgeable about pesticides or most pesticides out there in the market are very "effective". Either way, inefficient overuse of pesticides could indeed be promoted, which is in line with recent studies $[18,19]$.

To enter into further analysis of the perceived risks of rice farmers, a total of 28 risk sources was reduced using the varimax rotation factor analysis by their designated dimensions. The suitability of the application conditions was tested using KMO measure of sample adequacy and Barlett's test of sphericity. The KMO measure of sample adequacy for each risk dimension was production risk (0.82), market risk (0.68), financial risk (0.50), institutional risk (0.67), and human risk (0.79) and Barlett's test of sphericity was all significant at $1 \%$ level. These results denote data qualification for factor analysis [13]. The latent root criterion (Eigenvalues $>1$ ) suggested the use of three factors explaining the production risk with a total variance explained of $66.10 \%$. Each remaining risk dimension is reduced into one sole factor with the total variance explained of market risk (55.02\%), financial risk $(81.33 \%)$, institutional risk $(71.12 \%)$, and human risk $(66.12 \%)$.

Factor 1-7 can best be interpreted as: "input and sowing"; "climatic conditions"; "pest and disease"; "market"; "financial"; "institutional"; and "human". Factor 1, input and sowing, comprises of risk items related to input and sowing issues. Variables such as low germination rate of seeds, low yield varieties, seed damage, and poor quality fertilizer/pesticide load significantly on this factor. Factor 2 reflects natural hazards including heavy rain, drought, and storm. Factor 3 loads significantly and solely from the risk item of pest and diseases of plants. Factor 4, market, has high loadings on high and fluctuating input price, the instability of inputs supply, low and unstable selling price, and market inaccessibility. Factor 5 consists of high loading risk items related to financial issues. Heavy loadings of institutional risk items constitute Factor 6. Factor 7 comprises of human-related risk items.

\section{Perceptions of Risk Mitigation Strategies}

In this research, 22 risk mitigating strategies were investigated. The efficacy of risk management strategies was rated on a 7-point Likert scale with 1 as absolutely not effective and 7 as absolutely effective.

The descriptions and ranks of risk management strategies can be found in the second and fourth columns of Table 4. Detailed descriptive statistics such as means, standard deviations, and ranks are presented in the descending order of magnitude in Table 5. Management strategies were classified into four clusters of very efficient (average score $>6.0$ ), highly effective (average score 5.5-6.0), moderate (average score 4.0-5.5), and minimally efficient (average score $<4.0$ ).

The first cluster incorporates make use of the combined harvester, and adoption of certified varieties with average scores of 6.63 , and 6.38 , respectively. The second cluster involves five mitigating strategies with average scores ranged from 5.52 to 5.87 and are agreed as highly effective in alleviating risks. The next 13 strategies fall into the third cluster with average scores ranged from 4.35 to 5.48. Cooperative/farmer-group participation and ensure credit arrangement before cropping constitute the last cluster with average scores of 3.47 and 3.21, respectively.

$92.78 \%$ of farmers perceived the usefulness of the combined harvester as a very efficient and most important risk-mitigating strategy. This provides evidence on the risk-abating role of the combined harvester, particularly to solve the risk of unmatched sowing schedule and potentially increase the harvesting speed in case of unfavorable natural hazards such as storm or flood, which, in turn, results in minimal losses.

The second-most important risk-reducing strategy is the adoption of certified varieties - a very efficient measure, which was agreed by $89.18 \%$ of farmers. Rice yield of An Giang province was on average 6.25 ton/ha among the highest group in the Mekong Delta [20]. This connects to the fact that farmers understand the essential role of sowing certified varieties. Next, selecting prestigious partners, either buyers or contractors, was perceived as highly effective by $73.71 \%$ of farmers 


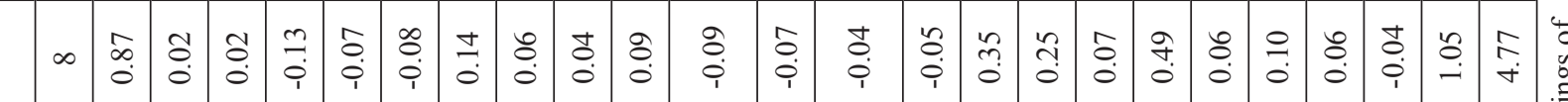

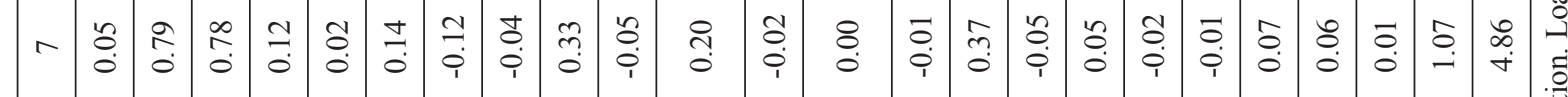

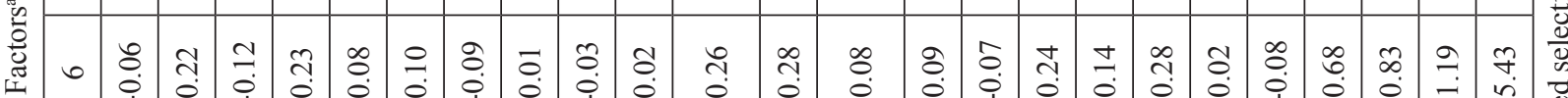

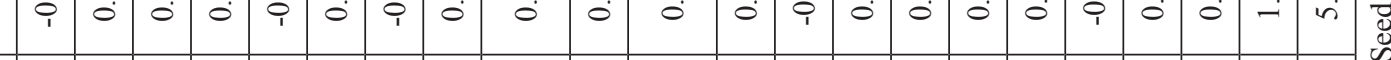

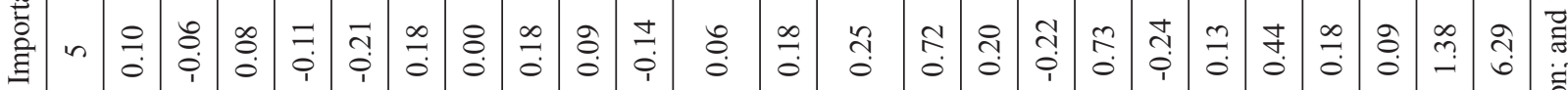

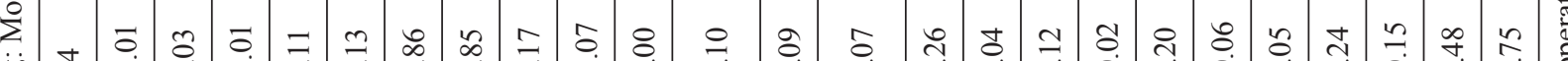

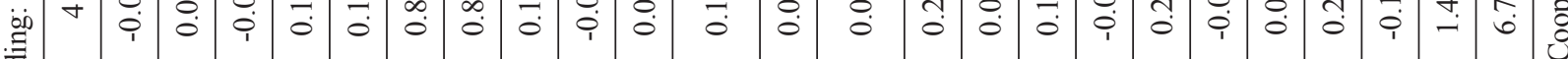

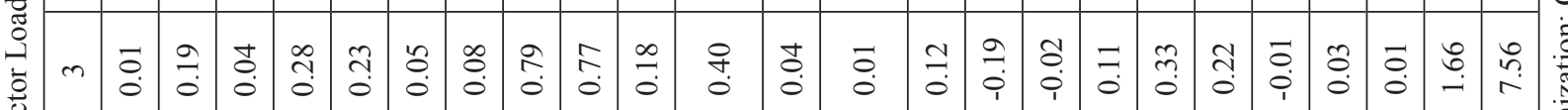

菏

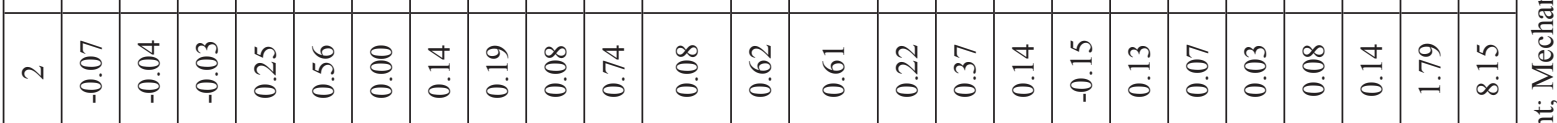

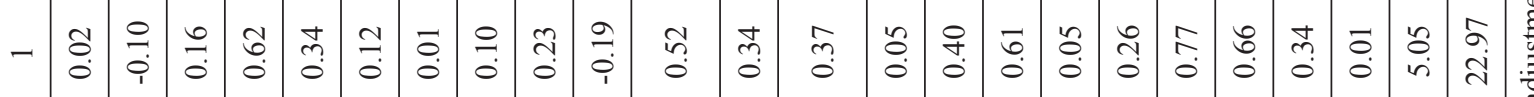

$\sum_{\mathbb{E}}^{\mathbb{E}}$

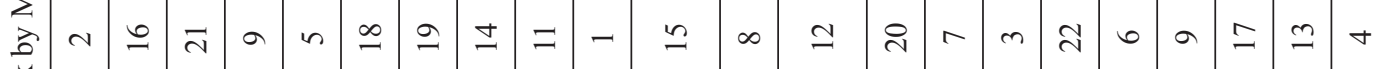

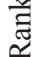

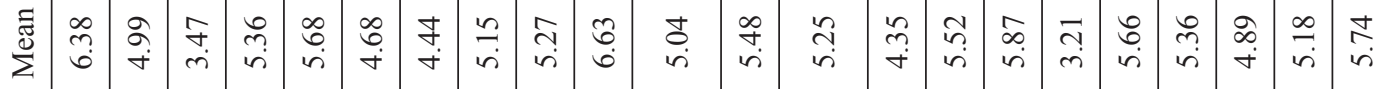

政

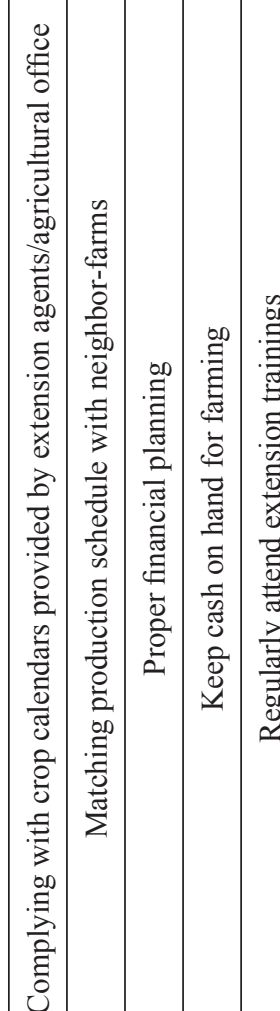

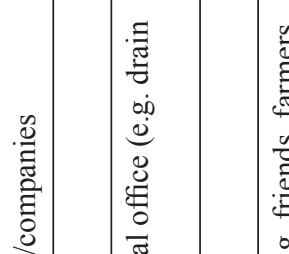

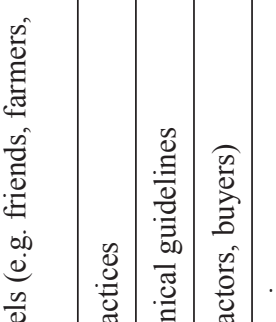

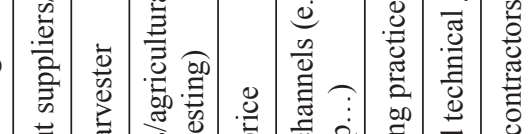

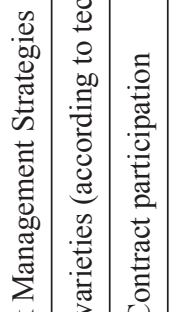

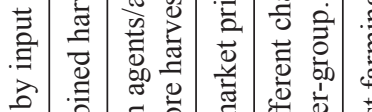

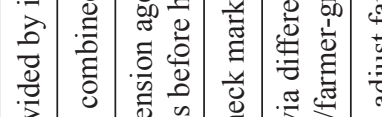

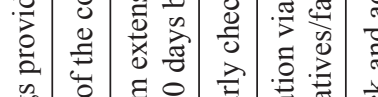

离

ठ

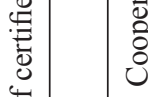

:

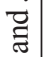

范

章

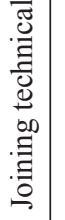

总至

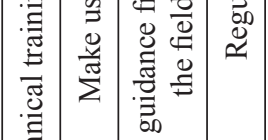

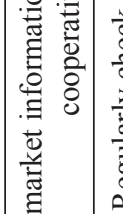

.

हี
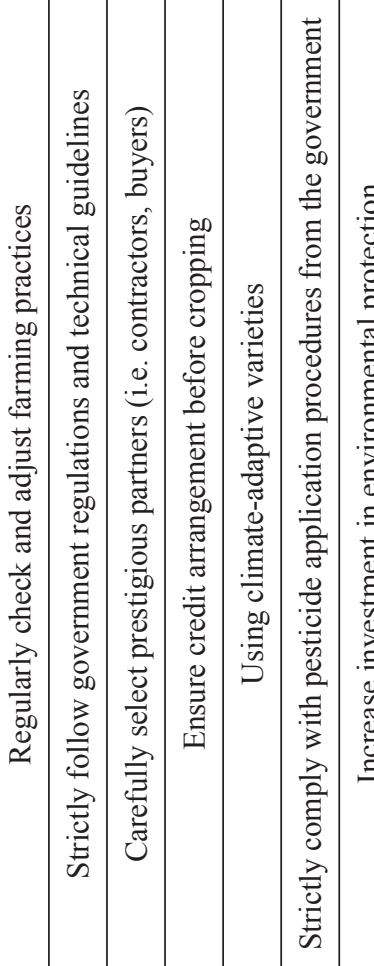

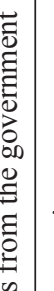

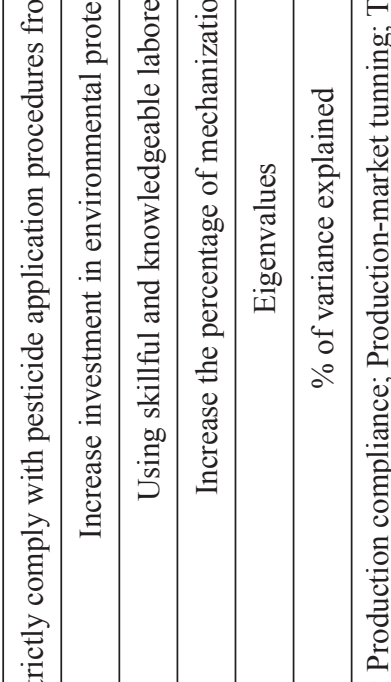

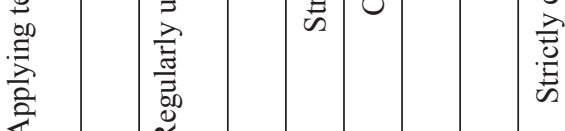

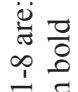

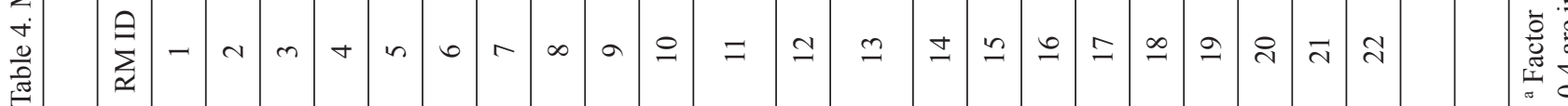


Table 5. Means, Standard Deviations and Ranks of Risk Management Strategies.

\begin{tabular}{|c|c|c|c|c|c|}
\hline RM ID & Risk Management Strategies & $\mathrm{N}$ & Mean & Std. Dev. & $\begin{array}{l}\text { Rank by } \\
\text { Mean }\end{array}$ \\
\hline 10 & Make use of the combine harvester & 194 & 6.63 & 0.82 & 1 \\
\hline 1 & Adoption of certified varieties (according to technical guidance) & 194 & 6.38 & 0.94 & 2 \\
\hline 16 & Carefully select prestigious partners (i.e. contractors, buyers) & 194 & 5.87 & 1.62 & 3 \\
\hline 22 & Increase the percentage of mechanization & 194 & 5.74 & 1.76 & 4 \\
\hline 5 & Matching production schedule with neighbor-farms & 194 & 5.68 & 1.29 & 5 \\
\hline 18 & Using climate-resistant varieties & 194 & 5.66 & 1.58 & 6 \\
\hline 15 & Strictly follow government regulations and technical guidelines & 194 & 5.52 & 1.48 & 7 \\
\hline 12 & Regularly check market price & 194 & 5.48 & 1.43 & 8 \\
\hline 4 & Complying with crop scheduling provided by extension agents/agricultural office & 194 & 5.36 & 1.83 & 9 \\
\hline 19 & Strictly comply with pesticide application procedures from the government & 194 & 5.36 & 1.57 & 9 \\
\hline 9 & Joining technical trainings provided by input suppliers/companies & 194 & 5.27 & 1.54 & 11 \\
\hline 13 & $\begin{array}{l}\text { Regularly update market information via different channels (e.g. friends, farmers, } \\
\text { cooperatives/farmer-group...) }\end{array}$ & 194 & 5.25 & 1.51 & 12 \\
\hline 21 & Using skillful and knowledgeable laborers & 194 & 5.18 & 1.62 & 13 \\
\hline 8 & Regularly attend extension trainings & 194 & 5.15 & 1.69 & 14 \\
\hline 11 & $\begin{array}{l}\text { Applying technical guidance from extension agents/agricultural office (e.g. drain } \\
\text { the field } 10 \text { days before harvesting) }\end{array}$ & 194 & 5.04 & 1.73 & 15 \\
\hline 2 & Contract participation & 194 & 4.99 & 1.92 & 16 \\
\hline 20 & Increase investment in environmental protection & 194 & 4.89 & 1.66 & 17 \\
\hline 6 & Proper financial planning & 194 & 4.68 & 1.8 & 18 \\
\hline 7 & Keep cash on hand for farming & 194 & 4.44 & 1.91 & 19 \\
\hline 14 & Regularly check and adjust farming practices & 194 & 4.35 & 1.87 & 20 \\
\hline 3 & Cooperative/farmer-group participation & 194 & 3.47 & 2.17 & 21 \\
\hline 17 & Ensure credit arrangement before cropping & 194 & 3.21 & 2.05 & 22 \\
\hline
\end{tabular}

to mitigate a wide range of risk concerns which mostly derived from input and output issues. The results beef up the evidence of the success of the contract farming scheme being promoted by the local and central government [14]. A plausible hint for policy-makers is to involve reputable and trusted companies in designing and promoting related agricultural policies in terms of risk mitigation. Mechanization was the next perceived important strategy. Among Mekong Delta regions, the current percentage of mechanization applied in An Giang was reported as tillage and irrigation (95\%), sowing (48\%), harvesting (42\%) which are also among leading provinces in the country [21]. According to local experts and key farmers, despite the high integration of machinery in rice farming, the current technologies applied are not cutting-edge, let alone leftout phases such as sowing, pesticide spraying, etc. For that reason, the integration of mechanization should be both horizontal in terms of its coverage of all phases of farming, and vertical with reference to modernness of new techs such as AI, big data, and drones to unlock their power to the fullest potential, to facilitate further automation farming.

Matching production schedules with neighbor farms secured the next important position on the list. This management strategy is the solution to cope with production risks and to leverage nearby human resources. Farmers often follow crop calendars and technical guidance provided by local extension agents which were set out in accordance with changes consulted with scientists and policy-makers to facilitate not only the quality and productivity of the crop but also to meet the consumption demand serving domestic and export needs aligned with government orientation. Besides, simultaneous production also means utilizing resources more efficiently such as labor, machinery, and knowledge sharing, let alone enjoying the economies of scale on input purchasing or output selling.

Regarding input purchasing, farmers were wellaware of the severe impact of climate change in recent years, particularly the harshest saline intrusion in the history in the current year, which explains why the use 
of climate-adaptive varieties was considered among highly effective strategies.

Similar to the analysis of risk sources, 22 risk management strategies were reduced into 8 risk management factors using factor analysis and orthogonal rotation method. In this vein, the application conditions were also checked. The KMO measure of adequacy was 0.72 , and Bartlett's test of sphericity was significant at the $1 \%$ level. These results satisfy the application conditions. The latent root criterion suggested 8 factors (total variance explained of $66.82 \%$ ). Factors $1-8$ were grouped into: "production compliance"; "productionmarket tunning"; "technical training"; "financial management"; "farming adjustment"; "mechanization"; "cooperation"; and "seed selection".

Factor 1, production compliance, is contributed by variables regarding the compliance of production practices such as complying with crop calendars and applying technical guidance provided by extension/ agricultural office, strictly follow pesticide application procedure, and investment in environmental protection, strictly follow government regulations and technical guidelines, and carefully select prestigious partners.
Factor 2 is labeled production-market tunning because of the heavy loadings of matching production schedule with neighbor-farms, regularly update market information, regularly check the market price, and make use of the combined harvester. Factor 3 , technical training, includes high loadings of the following variables: regularly attend extension training, joining technical training provided by input suppliers/ companies. Factor 4, financial management, represents financial practices such as proper financial planning, and keep cash on hand for farming. Factor 5 is considered as farming adjustment because it involves the heavy loadings of regularly check and adjust farming practices, investment in environmental protection, and ensure credit arrangement before cropping. It is also worth noting that some high cross-loadings of applying technical guidance from extension/agricultural office and increase investment in environmental protection were observed. This implies that the application of technical guidance from the extension/agricultural office plays a key role in the production process. Also, farmers should incorporate environmental protection practices into the production process and constantly

Table 6. Regression Results for Sources of Risk.

\begin{tabular}{|c|c|c|c|c|c|c|c|}
\hline \multirow[b]{2}{*}{ Independent variables } & \multicolumn{7}{|c|}{ Sources of Risk } \\
\hline & $\begin{array}{c}\text { Input } \\
\text { \& sowing }\end{array}$ & $\begin{array}{c}\text { Climatic } \\
\text { Conditions }\end{array}$ & $\begin{array}{c}\text { Pest } \\
\text { \& Disease }{ }^{\mathrm{b}}\end{array}$ & Market & Financial $^{\mathrm{b}}$ & Institutional $^{\mathrm{b}}$ & Human \\
\hline Gender & $\begin{array}{c}0.317 \\
(0.242)\end{array}$ & $\begin{array}{l}-0.239 \\
(0.245)\end{array}$ & $\begin{array}{l}-0.186 \\
(0.218)\end{array}$ & $\begin{array}{l}0.418^{*} \\
(0.242)\end{array}$ & $\begin{array}{c}0.105 \\
(0.206)\end{array}$ & $0.111(0.244)$ & $\begin{array}{l}-0.323 \\
(0.249)\end{array}$ \\
\hline Extension & $\begin{array}{l}-0.015 \\
(0.253)\end{array}$ & $\begin{array}{c}0.240 \\
(0.256)\end{array}$ & $\begin{array}{l}-0.186 \\
(0.220)\end{array}$ & $\begin{array}{c}0.161 \\
(0.254)\end{array}$ & $\begin{array}{c}0.059 \\
(0.264)\end{array}$ & $0.361(0.245)$ & $\begin{array}{c}-0.001 \\
(0.261)\end{array}$ \\
\hline Age & $\begin{array}{l}-0.011 \\
(0.008)\end{array}$ & $\begin{array}{l}-0.003 \\
(0.008)\end{array}$ & $\begin{array}{c}0.022 * * \\
(0.007)\end{array}$ & $\begin{array}{l}-0.009 \\
(0.008)\end{array}$ & $\begin{array}{l}0.0007 \\
(0.008)\end{array}$ & $\begin{array}{c}-0.014 * * \\
(0.006)\end{array}$ & $\begin{array}{c}0.006 \\
(0.008)\end{array}$ \\
\hline Edu & $\begin{array}{l}-0.016 \\
(0.027)\end{array}$ & $\begin{array}{c}0.012 \\
(0.028)\end{array}$ & $\begin{array}{c}0.028 \\
(0.026)\end{array}$ & $\begin{array}{c}-0.077 * * * \\
(0.027)\end{array}$ & $\begin{array}{c}-0.054 * * \\
(0.022)\end{array}$ & $\begin{array}{c}-0.053 * * \\
(0.025)\end{array}$ & $\begin{array}{c}0.040 \\
(0.028)\end{array}$ \\
\hline Exp & $\begin{array}{l}0.014^{*} \\
(0.008)\end{array}$ & $\begin{array}{c}-0.015^{*} \\
(0.008)\end{array}$ & $\begin{array}{c}-0.025^{* *} \\
(0.008)\end{array}$ & $\begin{array}{c}0.003 \\
(0.008)\end{array}$ & $\begin{array}{c}-0.002 \\
(0.007)\end{array}$ & $\begin{array}{l}0.012 * \\
(0.007)\end{array}$ & $\begin{array}{c}0.008 \\
(0.008)\end{array}$ \\
\hline Farm size & $\begin{array}{l}-0.090^{*} \\
(0.052)\end{array}$ & $\begin{array}{c}0.074 \\
(0.053)\end{array}$ & $\begin{array}{l}-0.057 \\
(0.050)\end{array}$ & $\begin{array}{c}0.044 \\
(0.052)\end{array}$ & $\begin{array}{c}0.012 \\
(0.051)\end{array}$ & $\begin{array}{c}-0.111^{* *} \\
(0.050)\end{array}$ & $\begin{array}{l}-0.055 \\
(0.053)\end{array}$ \\
\hline Income diversification & $\begin{array}{c}0.351^{* *} \\
(0.165)\end{array}$ & $\begin{array}{c}0.119 \\
(0.167)\end{array}$ & $\begin{array}{l}-0.071 \\
(0.166)\end{array}$ & $\begin{array}{l}0.312 * \\
(0.165)\end{array}$ & $\begin{array}{c}-0.065 \\
(0.167)\end{array}$ & $\begin{array}{l}0.325^{*} \\
(0.169)\end{array}$ & $\begin{array}{c}0.088 \\
(0.170)\end{array}$ \\
\hline Cooperative & $\begin{array}{l}-0.051 \\
(0.145)\end{array}$ & $\begin{array}{l}0.272^{*} \\
(0.147)\end{array}$ & $\begin{array}{l}-0.192 \\
(0.143)\end{array}$ & $\begin{array}{l}-0.069 \\
(0.145)\end{array}$ & $\begin{array}{l}-0.023 \\
(0.156)\end{array}$ & $0.022(0.153)$ & $\begin{array}{c}0.086 \\
(0.150)\end{array}$ \\
\hline Constant & $\begin{array}{c}0.302 \\
(0.563)\end{array}$ & $\begin{array}{c}-0.009 \\
(0.570)\end{array}$ & $\begin{array}{l}-0.177 \\
(0.506)\end{array}$ & $\begin{array}{c}0.200 \\
(0.564)\end{array}$ & $\begin{array}{c}0.218 \\
(0.496)\end{array}$ & $0.549(0.539)$ & $\begin{array}{l}-0.376 \\
(0.580)\end{array}$ \\
\hline R-squared & 0.089 & 0.068 & 0.098 & 0.087 & 0.025 & 0.094 & 0.034 \\
\hline R-squared adjusted & 0.050 & 0.028 & 0.059 & 0.048 & 0.016 & 0.055 & 0.007 \\
\hline Durbin-Watson statistics & 1.025 & 1.498 & 1.430 & 1.599 & 1.609 & 1.251 & 1.222 \\
\hline Breusch-Pagan test ${ }^{a}$ & $\begin{array}{c}0.06 \\
(0.800)\end{array}$ & $2.22(0.136)$ & $2.96(0.085)$ & $0.46(0.496)$ & $4.18(0.040)$ & $9.38(0.002)$ & $0.04(0.848)$ \\
\hline
\end{tabular}

Standard Errors in parentheses.

Asterisks $*, * *, * * *$ denote levels of significance of $10 \%, 5 \%$, and $1 \%$, respectively.

${ }^{a}$ Breusch-Pagan statistics of the original regressions and $\mathrm{p}$-values are in parentheses.

${ }^{\mathrm{b}}$ White consistent standard error and covariance estimation. 
adjust these environmental-friendly farming practices to resolve related risks. Factor 6 , mechanization and human, is derived from the heavy loadings of increase the percentage of mechanization and using skillful and knowledgable laborers. Contract participation and cooperative/farmer-group participation constitute Factor 7, cooperation. Finally, Factor 8 - seed selection, addresses the adoption of certified varieties, and the use of climate-adaptive varieties.

\section{Relationship between Risk Perceptions} and Socio-Demographic Characteristics

Table 6 illustrates the regression results. $R^{2}$ of all models were relatively small, ranging from 0.02 to 0.09 . This is analogous to previous empirical risk perception studies $[4,5]$.

VIFs ranged between 1.05 and 1.64, indicating that multicollinearity was not a problem. The BreuschPagan test denotes the rejection of the null hypothesis of homoscedasticity of the equation for factors "Pest and diseases", "financial", and "institutional". Hence, robust standard errors were applied to re-estimate these equations. Durbin-Watson statistics of all models ranged between 1.02 and 1.60 , confirms the absence of the first-order autocorrelation problem.

The regression results revealed that male farmers were more sensitive to market risks than their female counterparts. The nature of farming in agriculture requires lots of physical labor which entitled to be the duty of the male heads, which also provides them the power to make major decisions such as buying inputs and selling outputs. This responsibility explains why male farmers tend to be more sensitive to market risks to fulfill their duties.

Regarding age, older farmers tended to perceive greater production risk, in this case, pest and disease risk, than younger farmers. However, older farmers were less aware of the institutional risks than younger ones. These findings are consistent with the case of catfish farming [4] but contrast the case of rice farming in Bangladesh [3].

Farmers with lower education perceived more of market, financial, and institutional risks. This contrasts the situation in Bangladesh where farmers with a higher education focus more on market risk [3]. Interestingly, in the production risk category, more experienced farmers perceived more of the input and sowing risk and institutional risk while less of climatic risks and pest and disease risks. Perhaps, local farmers have experience in dealing with natural hazards and pest and disease issue - analogous to the case of Pakistan farmers [22,23], however, lack of the capability to control institutional issues and input-sowing related risks such as unable to obtain quality pest-resistant varieties or quality pesticide or fertilizer. Given small farmers in this study, farmers with lesser farm sizes discern riskier at input and sowing and institutional risks. Indeed, more experienced farmers with smaller farm sizes were more risk-averse than those with less experience but with larger farms. In other words, ones with more constrained resources tend to be more cautious in decision-making regarding uncertainties. The results also demonstrated that farmers who had off-farm income perceived more of input and sowing, market, and institutional risks. In this situation, income diversification might be one of the coping solutions chosen similar to the situation reported in Bangladesh $[3,8,24]$. Being a cooperative member helps to reduce other production risk perceptions, however resulted in exacerbating the perception of climatic risks. This was probably because of the propaganda of the impact of climate change via the cooperative or farmer groups; and that while technical knowledge dissemination mitigates potential production risks, climate risks are uncontrollable.

\section{Relationship between Risk Management Strategies and Risk Perceptions and Socio-Demographic Characteristics}

Table 7 presents the regression results of the analysis. $R^{2}$ of all models were between 0.09 to 0.51 . VIFs showed no existence of the multicollinearity problem, varying between 1.07 and 1.75 .

Durbin-Watson statistics denoted no firstdegree autocorrelation. Breush-Pagan test suggested the re-estimation with White's consistent robust standard errors on factors "production compliance", "production-market tunning", "financial management", "mechanization", and "seed selection".

Regarding gender, female and male farmers develop different viewpoints over the effectiveness of distinct risk management strategies. While female farmers perceived production compliance and production-market tunning as more important, their male counterparts valued more the resort of farming adjustment. Expectably, farmers, who received extension training, expressed a positive perception on the impact of technical training, farming adjustment, and seed selection. These results indicated the effective role of the extension in strengthening farmers' technical knowledge to tackle risks. The dissimilar impacts of age, education, experience, and cooperative across risk management strategies were also detected. While older farmers evaluated farming adjustment and mechanization as more important, younger ones valued more the crucial role of seed selection strategy. More educated farmers were more conscious of the efficacy of production compliance, financial management, farming adjustment, but less for seed selection. More experienced farmers rated the role of production compliance highly but seem underrated the cooperation strategy. Farmers who were members of a cooperative tended to be more concerned with the impact of cooperation and less with mechanization. This can be explained that small farmers in a cooperative often locate in the same region which facilitates the helping 


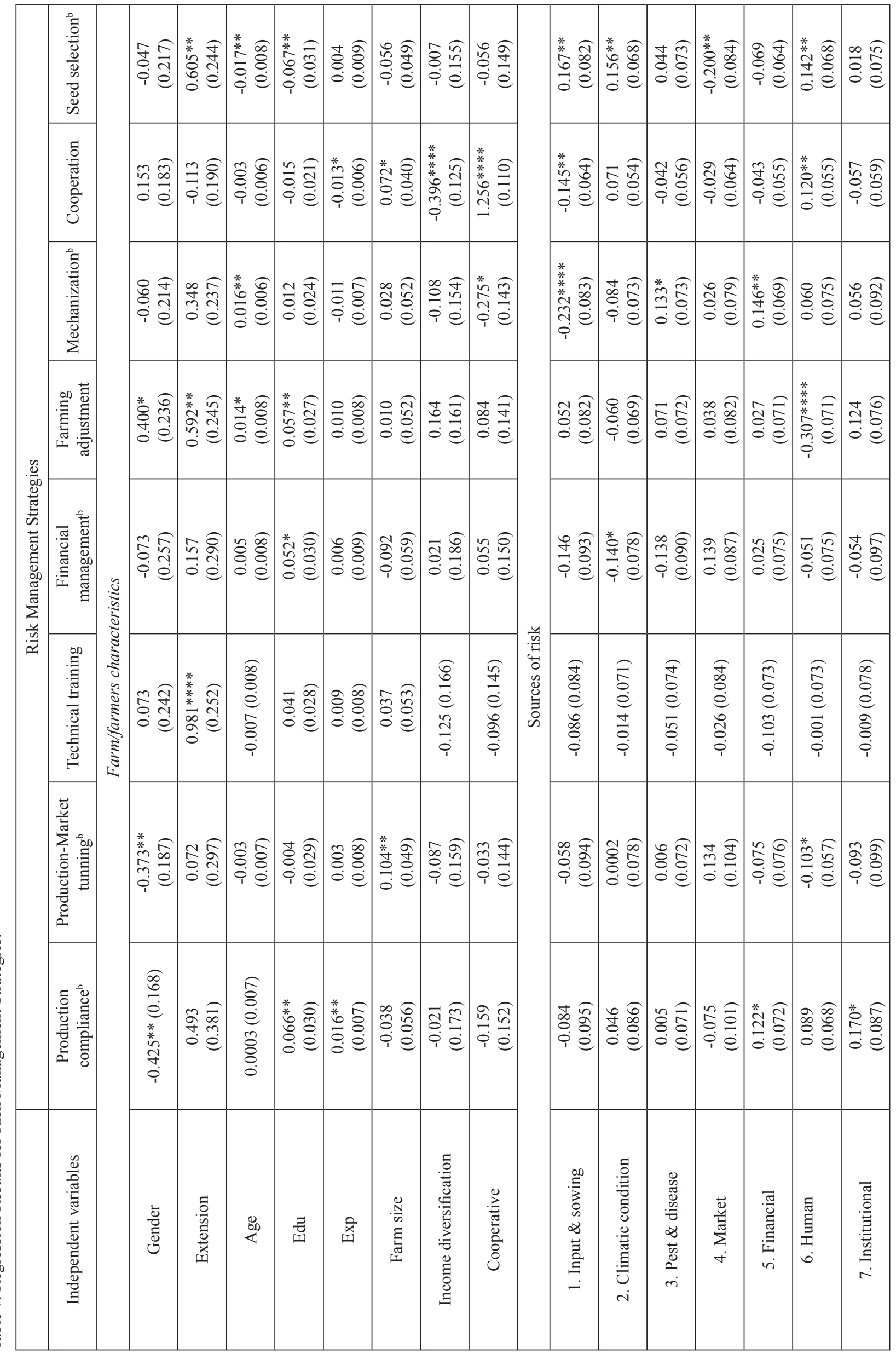




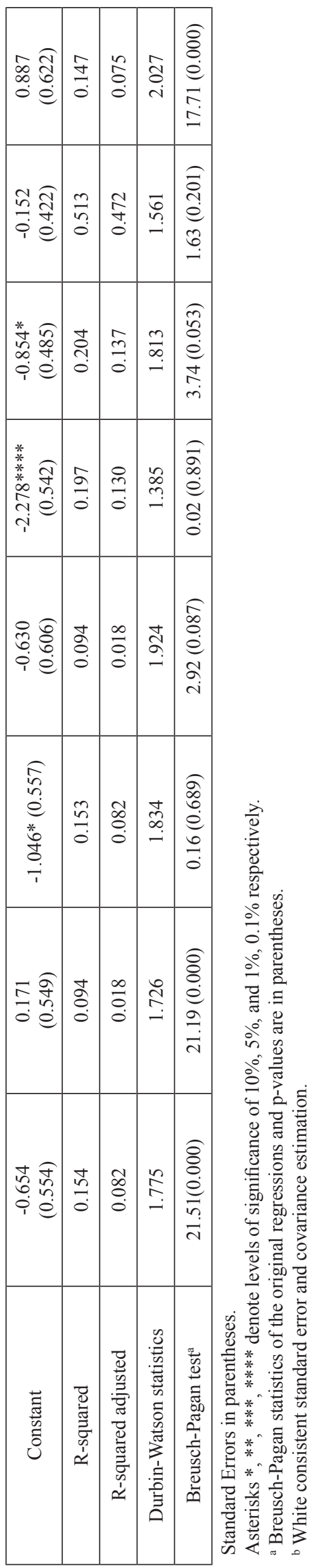

mechanism for a win-win relationship such as physical labor sharing which overcome the need for expensive machinery that they could not afford. The cooperation seems stronger proportionate with the increase in farm size. Also, larger farms were more aware of adjusting/tunning up their production practices to adapt to changes happening in the market. The negative coefficient of income diversification reinforced the fact that full-time farmers understand the importance of cooperation as a risk management strategy, perhaps because their livelihood greatly depends on the sole source of income, similar to the case of shrimp farmers in Bangladesh [8].

Studies have shown that risk perceptions significantly influence not only economic behaviors but also risk-mitigating decisions regarding perceived risks $[4,5,8]$. Similar to these studies, this research confirms the multidimensional aspect between risk perceptions and management strategies, meaning multiple strategies are required to mitigate a certain risk source and multiple risk perceptions drive the application of a specific risk management strategy.

It is reasonable to expect that seed selection influences input and sowing risk directly. However, counterintuitively, farmers who perceived the important role of input and sowing risk tended to underestimate the effectiveness of mechanization and cooperation strategies. Given that the input and sowing risk is constituted majorly by input risks (as presented in Table 2), which deems uncontrollable, the problem is unraveled. The perceived impact of the climatic condition on the perceptions of financial management and seed selection unveiled farmers' preferences of coping strategies in favor of selecting certified and climate adaptive varieties and neglecting the financial management strategy. Local farmers seem to underestimate the role of financial management strategy, which is useful for solving the consequences of natural hazards. Next, the perceived impact of pest and diseases could drive the decision of increasing the percentage of mechanization, especially machineaid pest control. Regarding the perception of market risk, seed selection was apparently one of the least important and relevant strategies to deal with market risk. The regression results further suggested that farmers dealing with financial risk would strictly comply with good production practices and tend to integrate more mechanization into farming because they have to maximize their sole income source to tackle the problem of external financial inaccessibility. Perceived human risk has a negative impact on production-market tunning and farming adjustment but positive on cooperation and seed selection strategies. The increasing impacts of human risk might incite farmers to endorse more cooperation and seed selection practices. More cooperation to compensate for the lack of skills and experience is understandable, how about seed selection? Connecting the dots, choosing certified and climate-resistant varieties directly abridge 
other production risks (i.e. input and sowing, climatic condition) which somehow relax the constrains on required labor competency. Last, the ascending impact of institutional risk urged the perceived importance of the production compliance strategy. This showcases farmers' awareness of on-going policy changes and their pivotal roles in the production process.

\section{Conclusions and Limitations}

The objective of this present study is to provide empirical insights into Vietnamese rice farmers' perceptions of risk and risk management strategies and the relationship between these factors with farmers' sociodemographic characteristics.

The results highlighted the most important impacts of the low and unstable selling price, the instability of inputs supply, high and fluctuating input price, lack of awareness about health protection in pesticide use, and poor quality pesticide. On the other hand, make use of the combined harvester, adoption of certified varieties, selecting prestigious partners, mechanization, matching production schedule with neighbor-farms, and using climate-adaptive varieties were perceived as the most important mitigation strategies to sustain farmers' income and productivity.

The regression analysis also provided evidence on the significant influences of selected sociodemographic characteristics on the perception of risks and management strategies. The discrepancy of impacts of sociodemographic characteristics on risk perceptions and management reflected the complicated decision patterns of separate farmers made toward certain risks and their mitigation options. Notably, farmers' opting for a specific management strategy was fueled by multiple risk perceptions, either positive or negative. The results further confirmed the findings of recent risk studies $[2,5,6]$. This also concludes that there is no 'one size fits all' approach suitable to promote the adoption of a certain risk management strategy. For that reason, tailored policies are needed to promote distinct risk management strategies.

The first limitation is derived from this conclusion that the readers might want to take caution in generalizing or interpreting this finding as it is highly contextual. Furthermore, this research is limited in its cross-sectional data collection method and the studied target was smallholders only. Moreover, base on the low $R^{2}$ of models, there are still many other left-out potential predictors that future researchers would want to look at such as descriptive norms, prescriptive norms, and many more.

\section{Acknowledgments}

We want to express our sincere thanks to all farmers who participated in the study and the assistance of local extensionists as well as the enumerators. Funding from Nong Lam University is also acknowledged. Appreciation is also paid toward the Executive Editor, the Editor-in-Chief, and also anonymous reviewers for their valuable comments to improve the manuscript. We are also grateful for technical guidance of Dr. Le Cong Tru.

\section{Conflict of Interest}

The authors declare no conflict of interest.

\section{References}

1. FLATEN O., LIEN G., KOESLING M., VALLE P.S., EBBESVIK M. Comparing risk perceptions and risk management in organic and conventional dairy farming: empirical results from Norway. Livestock Production Science, 95 (1), 11, 2005.

2. BISHU K.G., O'REILLY S., LAHIFF E., STEINER B. Cattle farmers' perceptions of risk and risk management strategies: evidence from Northern Ethiopia. Journal of Risk Research, 21 (5), 579, 2018.

3. ISLAM M.D.I., RAHMAN A., SARKER M.N.I., SARKER M.S.R., JIANCHAO L. Factors Influencing Rice Farmers' Risk Attitudes and Perceptions in Bangladesh amid Environmental and Climatic Issues. Pol. J. Environ. Stud., 30 (1), 177, 2021.

4. LE T.C., CHEONG F. Perception of risk and risk management in Vietnamese catfish farming: An empirical study. Aquaculture Economics \& Management, 14 (4), 282-314, 2010.

5. ALAM M.A., GUTTORMSEN A.G. Risk in aquaculture: farmers' perceptions and management strategies in Bangladesh. Aquaculture Economics \& Management, 23 (4), 359, 2019

6. MERANER M., FINGER R. Risk perceptions, preferences and management strategies: evidence from a case study using German livestock farmers. Journal of Risk Research, 22 (1), 110, 2019.

7. AHSAN D.A., ROTH E. Farmers' Perceived Risks and Risk Management Strategies in an Emerging Mussel Aquaculture Industry in Denmark. Marine Resource Economics, 25 (3), 309, 2010.

8. AHSAN D.A. Farmers' motivations, risk perceptions and risk management strategies in a developing economy: Bangladesh experience. Journal of Risk Research, 14 (3), 325, 2011.

9. SJÖBERG L., MOEN B.-E., RUNDMO T. Explaining Risk Perception. An Evaluation of the Psychometric Paradigm in Risk Perception Research; Rotunde Publikasjoner: Trondheim, 2004.

10. DANG H.D., DAM A.H.T., PHAM T.T., NGUYEN T.M.T. Determinants of credit demand of farmers in Lam Dong, Vietnam: A comparison of machine learning and multinomial logit. Agricultural Finance Review, 80 (2), 269, 2019.

11. VAN RAAIJ, W.F. Economic psychology. Journal of Economic Psychology, 1 (1), 1, 1981.

12. CRANE L., GANTZ G., ISAACS S., JOSE D., SHARP R. Introduction to Risk Management. Understanding Agricultural Risks: Production, Marketing, Financial, 
Legal, Human, $2^{\text {nd }}$ ed., Extension Risk Management Education and USDA-Risk Management Agency: 2013.

13. HAIR F.J., BLACK W., BABIN B., ANDERSON R. Multivariate Data Analysis: A Global Perspective; Pearson Education: New Jersey, 2010.

14. DANG H., PHAM T. Predicting Contract Participation in the Mekong Delta, Vietnam: A Comparison Between the Artificial Neural Network and the Multinomial Logit Model. Journal of Agricultural \& Food Industrial Organization, 2021.

15. RIWTHONG S., SCHREINEMACHERS P., GROVERMANN C., BERGER, T. Agricultural commercialization: Risk perceptions, risk management and the role of pesticides in Thailand. Kasetsart Journal of Social Sciences, 38 (3), 264, 2017.

16. STADLINGER N., BERG H., VAN DEN BRINK P.J., TAM N.T., GUNNARSSON J.S. Comparison of predicted aquatic risks of pesticides used under different rice-farming strategies in the Mekong Delta, Vietnam. Environmental Science and Pollution Research, 25 (14), 13322, 2018.

17. HASHEMI S.M., ROSTAMI R., HASHEMI M.K., DAMALAS C.A. Pesticide Use and Risk Perceptions among Farmers in Southwest Iran. Human and Ecological Risk Assessment: An International Journal, 18 (2), 456, 2012.
18. SALAZAR C., RAND J. Pesticide use, production risk and shocks. The case of rice producers in Vietnam. Journal of Environmental Management, 253, 109705, 2020.

19. TU V.H., CAN N.D., TAKAHASHI Y., KOPP S.W., YABE M. Modelling the factors affecting the adoption of ecofriendly rice production in the Vietnamese Mekong Delta. Cogent Food \& Agriculture, 4 (1), 1432538, 2018.

20. GSO. Statistical Year Book; GSO: Hanoi, 2019.

21. HIEN T. Agricultural extension forum for agriculture "mechanization in rice production". Mard: mard.gov.vn, 2019.

22. RIZWAN M., PING Q., SABOOR A., AHMED U.I., ZHANG D., DEYI Z., TENG L. Measuring rice farmers' risk perceptions and attitude: Evidence from Pakistan. Human and Ecological Risk Assessment: An International Journal, 26 (7), 1, 2019.

23. ULLAH R., SHIVAKOTI G.P., ALI G. Factors effecting farmers' risk attitude and risk perceptions: The case of Khyber Pakhtunkhwa, Pakistan. International Journal of Disaster Risk Reduction, 13, 151, 2015.

24. KABIR M.J., CRAMB R., ALAUDDIN M., GAYDON D.S. Farmers' perceptions and management of risk in ricebased farming systems of south-west coastal Bangladesh. Land Use Policy, 86, 177, 2019. 